\title{
DESCOBERTAS, PERCURSOS E TRANSGRESSÕES: AS IDENTIDADES POSTAS EM XEQUE EM INSUBMISSAS LÁGRIMAS DE MULHERES
}

\author{
DISCOVERIES, PATHS AND TRANSGRESSIONS: \\ IDENTITIES PUT IN CHECK IN INSUBMISSIBLE WOMEN'S TEARS
}

\author{
Dauana Pinheiro Leal do Santos ${ }^{1}$ \\ [https://orcid.org/0000-0002-6363-2529] \\ DOI: 10.30612/raido.v15i38.14399
}

\begin{abstract}
RESUMO: Neste artigo, discute-se as representaçōes das identidades insurgentes formadas em contextos sociais historicamente alicerçados em padróes patriarcais, racistas, sexistas e heteronormativos. Analisa-se, a partir dos contos "Natalina Soledade" e "Isaltina Campo Belo", que fazem parte obra Insubmissas Lágrimas de Mulheres (2016), de que modo essas identidades consideradas desviantes sâo formadas, quais os percursos percorridos para alcançar a auto-afirmaçăo e como o projeto político-literário de Conceiçấo Evaristo pautado na "escrevivência" contribui para o enfrentamento e resistência desses sujeitos. A metodologia aporta-se em uma pesquisa bibliográfica de cunho qualitativo, baseia-se nos estudos sobre Identidade, representaçăo e diferença do Tomaz Tadeu da Silva (2012) e Stuart Hall (2013). A relaçâo da literatura e identidade perpassa pelo estudo de Zilá Bernd (2003). Além desses estudiosos, tem-se as contribuiçōes Audre Lorde (2019) e Bell Hooks (2020). A escrevivência constrói formas de afirmaçăo identitária, na medida em que os contos convocam a reconhecer as múltiplas diferenças entre as mulheres negras. Rompe com os modelos de identidades pautados na opressâo, deslocando-as para que novas identidades emergentes sejam construídas através da transgressăo, luta e resistência.
\end{abstract}

Palavras-chave: Identidade; Representaçăo; Literatura; Conceiçâo Evaristo.

ABSTRACT: This article, discusses the representations of insurgent identities formed in social contexts historically based on patriarchal, racist, sexist and heteronormative patterns. Based on the short stories "Natalina Soledad" and "Isaltina Campo Belo", which are part of the work Insubmissas Lágrimas de Mulheres (2016), we analyze how these identities considered deviant are formed, what are the paths taken to achieve self-affirmation and how the political-literary project of Conceiçấo Evaristo based on "experience" contributes to the confrontation and resistance of these subjects. The methodology is supported by a qualitative bibliographical research, based on studies on Identity, representation and difference by Tomaz Tadeu da Silva (2012) and Stuart Hall (2013). The relationship between literature and identity is permeated by the study

1 Universidade do Estado da Bahia (UNEB) 
of Zilá Bernd (2003). In addition to these scholars, there are the contributions of Audre Lorde (2019) and Bell Hooks (2020). Experience constructs forms of identity affirmation as the short stories call for recognizing the multiple differences among black women. It breaks with models of identities grounded in oppression, displacing them so that new emergent identities are constructed through transgression, struggle, and resistance.

Keywords: Identity; Representation; Literature; Conceiçăo Evaristo.

\section{INTRODUÇÃO}

Os modelos tradicionais de ser e viver foram historicamente criados para manter os privilégios da classe dominante. Se por um momento buscarmos na memória eventos, narrativas históricas, perceberemos que as identidades do sujeito foram articuladas para cristalizarem determinados papéis sociais, sobretudo subalternos, e assim, por mais que as sociedades se modernizassem, o caráter essencializante atribuído às identidades dos sujeitos náo se desviariam. Desse modo, o controle seria mantido para o bem e a ordem comum.

Associadas às teorias biológicas, sobretudo as desenvolvidas no século XIX influenciadas pelos estudiosos europeus, as identidades foram se naturalizando como algo inato com o propósito de justificar as exclusōes e injustiças sociais. As leituras sobre o corpo sáo atravessadas por marcadores sociais. Fernandes e Souza (2016) argumentam que, tomar como um dado natural algo de caráter social e simbólico é elaborar uma visáo errônea sobre o corpo. Em relaçăo à questáo racista, as autoras explicam que em cada país o negro é compreendido de modo diferente, por exemplo. Podemos ampliar o ponto de vista para pensar a mulher, o gay, a lésbica.

Diante do exposto, concordamos com Tomaz da Silva (2012, p.76) ao afirmar que as identidades "somos nós que fabricamos no contexto das relaçôes culturais e sociais." Compreende-se o ato de criar como elemento importante dentro do processo de identificaçăo, no entanto a afirmaçăo exerce o papel crucial nessa dinâmica, pois demarca a presença do poder dentro de um território. Por isso, os grupos buscam a afirmaçáo através da imposiçáo identitária em relaçăo ao outro. Estabelece-se uma relaçáo conflituosa, na qual quem detém o poder de classificar possui também o privilégio de representar o seu grupo em detrimento de outro.

Logicamente cada grupo deve buscar mecanismos para representar a si mesmo, caso contrário corre o risco de continuar sendo objetificado nas narrativas hegemônicas. As mulheres negras foram, durante muito tempo, representadas de forma negativa na literatura nacional, como possuindo uma identidade unificada, ligadas à criaçăo de dados empíricos sobre a raça, mas a partir de uma perspectiva dominante, e por isso, bastava adicionar em uma personagem características que representassem todo o grupo. Dessa maneira, estava pronta a identidade folclórica, caricatural e generalizada. Contudo, apesar do silenciamento histórico, as escritoras negras buscam se autorrepresentarem, já que a literatura é um poderoso instrumento de representaçăo simbólica, exerce por assim dizer, o papel de organizar a sociedade. De acordo com Evaristo (2005, p.54) "Assenhoreando-se 'da pena', objeto representativo do poder falocêntrico branco, as escritoras negras buscam inscrever no corpus literário brasileiro imagens de uma autorrepresentação." 
Sendo assim, o objetivo desse artigo é analisar a partir dos contos "Natalina Soledad" e "Isaltina Campo Belo", que fazem parte obra Insubmissas Lágrimas de Mulheres (2016), de que modo as identidades consideradas desviantes das mulheres negras sâo formadas, quais os percursos percorridos para alcançar a auto-afirmaçăo e como o projeto político-literário de Conceiçăo Evaristo pautado na escrevivência, termo criado pela autora para definir o processo de escrita que nasce a partir das experiências dos grupos negros, contribui para o enfrentamento e resistência desses sujeitos.

É importante frisar que a escrevivência da autora é atravessada pelas vivências enquanto mulher e negra na sociedade brasileira. Contudo, năo é uma produçâo direcionada a um sujeito individualizado, mas abarca subjetividades coletivas, como ressalta Evaristo (2020, p.38) “Escrevivência surge de uma prática literária cuja autoria é negra, feminina e pobre. Em que o agente, o sujeito da açăo, assume o seu fazer, o seu pensamento, a sua reflexăo, năo somente como um exercício isolado, mas atravessado por grupos, por uma coletividade."

Vale ressaltar ainda que a produçáo de Evaristo soma-se a um conjunto de narrativas que buscam afirmar as identidades de sujeitos cujas vozes săo emergentes. Como afirma Zilá Bernd (2003) essas literaturas visam apropriar-se de um território no qual possam existir. Justamente por serem sujeitos que vivem em constante ameaça de apagamento.

\section{PODER FALOCÊNTRICO: IDENTIDADES AMEAÇADAS}

Na obra Insubmissas Lágrimas de Mulheres, as identidades das personagens em suas diversas dimensóes săo constantemente ameaçadas, pelo fato de fazerem parte de um universo de diferenças que nâo sâo consideradas legitimas. Sáo mulheres negras, que buscam se afirmar em meio a situaçōes que retiram o seu protagonismo e impôem papéis subalternizados para que cumpram sem contestar, pois no jogo da identidade quem tem mais poder simbólico dita as regras de acordo com os seus interesses, reafirmando sua identidade constantemente. No conto intitulado "Natalina Soledad", a personagem vivencia a rejeiçấo de seu pai por ter nascido menina. Para o pai, a masculinidade representa o símbolo do poder, a continuidade do patriarcado, enquanto o feminino é considerado inferior, cuja utilidade é servir. Neste sentido, a filha era "uma coisa menina" sem valor, como podemos notar no trecho do conto:

Natalina Soledad, tendo nascido mulher, a sétima depois dos seis homens, năo foi bem recebida pelo pai e náo encontrou acolhida no colo da máe. O homem garboso de sua masculinidade, que, a seu ver, ficava comprovada a cada filho homem nascido, ficou decepcionado quando lhe deram a notícia de que o sétimo rebento era uma menina. (EVARISTO, 2016, p.19)

A identidade de Natalina forjada nos moldes patriarcais, sob o signo da desvalorizaçăo já a aguardava antes mesmo de nascer. Tudo isso, porque o patriarcado concede poder e autoridade aos homens de controlar e oprimir as mulheres, como argumenta Hooks (2020, p. 145) “(...) o poder patriarcal, o poder que os homens usam para dominar mulheres, năo é apenas privilégio de homens brancos das classes alta e média, mas de todos os homens em nossa sociedade, independente de classe ou raça." 
Em se tratando de uma escrita feminina, Evaristo representa uma situaçăo constantemente debatida entre as feministas negras, que é o fato de os homens negros compartilharem de ideias sexistas. Como consequência de uma estrutura social a identidade dos homens negros estăo atravessadas pelo contexto no qual eles também buscam poder, desse modo concebem as mulheres como inferiores, meros objetos. Como podemos perceber no trecho a seguir:

De seu corpo náo podia ser, de sua rija semente jamais brotaria uma coisa menina. Sua mulher devia ter se metido com alguém e ali estava a prova. Uma menina! (...) tomou nojo do corpo desobediente dela, do corpo traidor de sua esposa. E Maria Anita Silveira, entre lamentos e desejos, mal amamentou a criança. Descuidouse propositalmente dela e até concordou que o pai nomeasse a filha de Troçoleia Malvina Silveira. A criança só herdou o Silveira no sobrenome, porque a ausência desse indicador familiar poderia levantar a suspeita de que algo desonroso manchava a autoridade dele. (EVARISTO, 2016, p.21)

Existem diversas maneiras de afirmar uma identidade e consequentemente o poder, dentre elas as mais eficazes sâo a inferiorizaçâo e a dominaçăo das outras. Para isso, busca-se criar instâncias as quais garantam que a identidade do opressor se torne a identidade de referência. De acordo com Silva (2012) identidade e diferença se interligam. E só existe afirmaçăo identitária em contraposiçăo as outras. Neste sentido, é estabelecido um binarismo associado às afirmaçôes positivas e negativas entre homem e mulher, branco e negro. Para Silva (2012, p.75) “a afirmaçāo (...) é uma parte de uma extensa cadeia de negaçóes, de expressóes negativas de identidades e diferenças." Esses discursos negativos a respeito da identidade que foi criada para alguém é um modo de formar uma aura de verdade, que vai sendo reafirmada através de outros mecanismos como a ciência, a religiăo por exemplo. No conto, o episódio da escolha do nome da personagem é uma metáfora de como a identidade da mulher é forjada. Troçoleia Malvina faz uma alusáo a troço, ou seja, coisa sem valor, Malvina é uma derivaçâo de mal, como é comumente apresentado nas narrativas cristăs.

Como explica Foucault (1996) em a Ordem do discurso, os sujeitos criam a partir da vontade de verdade tecnologias e instituiçôes legitimadoras de discursos verdadeiros. Desse modo, podemos pensar as construçōes identitárias, sobretudo as impostas, como uma vontade de poder. Segundo Foucault (1996):

Ora, a vontade de verdade, como os outros sistemas de exclusấo, apóia-se sobre um suporte institucional: é ao mesmo tempo reforçada e reconduzida por todo um compacto conjunto de práticas como a pedagogia, é claro, como um sistema de livros da ediçăo, das bibliotecas, como as sociedades de sábios outrora, os laboratórios hoje. Mas ela é também reconduzida, e sem dúvida, pelo modo como o saber é aplicado em uma sociedade, como é valorizado distribuído, repartido e de certo modo atribuído. (FOUCAULT, 1996, p.17)

A questâo identitária construída sob a ótica do dominante é articulada de modo eficaz para que as mulheres ajam sob a égide machista. Pois foram ensinadas a serem e a se comportarem de determinado modo. Como podemos ver no trecho do conto, a mâe da personagem analisada, descuidou da filha de modo proposital em obediência ao marido. Em outro episódio o comportamento da mâe fica mais evidente: 
A menina Silveira crescia a contragosto dos pais. Solitária, aprendera quase tudo por si mesma, desde o pentear dos cabelos até os mais difíceis exercícios de matemática, assim como se cuidar no período dos íntimos sangramentos. Dos cadernos e dos livros velhos desprezados pela prole masculina, que começava os estudos, ainda quando cada um precisava de auxílio para suspender a cueca, sozinha, ela recolhia suas liçóes. (EVARISTO, 2016, p.21)

Contudo, como meio de resistir à opressâo, a personagem desenvolveu a defesa decidindo reconstruir sua identidade através da mudança de nome, negando por assim dizer, as referências que a ligavam aos pais e a sua descendência. Autonomear-se é uma representaçăo simbólica do processo de criaçăo de uma nova identidade. Como é revelado no fragmento: "Tinha um só propósito. Um grande propósito. Inventar para si outro nome. E, para criar outro nome, para se rebatizar, antes era preciso esgotar, acabar, triturar, esfarinhar aquele que havia imposto" (EVARISTO, 2016, p.24).

Sobre essa questăo, Araújo (2018) afirma que as identidades construídas sob o signo de elementos subalternizantes devem ser (des)alinhavadas, para que novas identidades sejam costuradas tomando como base outros aspectos pautados na liberdade. É importante enfatizar que, ainda assim, o alinhavo se configura como uma costura provisória, pelo fato de as identidades náo serem fixas e estarem em constante processo de construçấo.

Em outro conto, “Isaltina Campo Belo", Evaristo também representa o conflito identitário da personagem, derivado de um contexto em que as regras pautadas no modelo conservador prevalecem. Isaltina experiencia por diversos momentos a construçáo, descobertas e desconstruçấo da identidade, até chegar ao ponto de identificaçấo que diverge dos modelos de comportamentos impostos para quem nasce no corpo feminino. Ainda criança, Isaltina percebia que era diferente das outras meninas.

Tive uma infância feliz, só uma dúvida me perseguia. Eu me sentia menino e me angustiava com o fato de ninguém perceber. Tinha me dado um nome errado, me tratavam de modo errado, me vestiam de maneira errada... estavam todos enganados. Era um menino (EVARISTO, 2016, p.57-58).

Isaltina năo se identificava com o que foi estabelecido como feminino, pois a identidade nâo é algo inato, mas é imposta a partir de interesses e leituras equivocadas sobre o corpo e papéis sociais. Pode-se observar que a formaçấo da identidade de gênero é marcada por incertezas sobre quem năo somos. Desse modo, estabelecemos pontos de diferenciaçấo que ocorre através do olhar sobre nós mesmos em consubstanciaçâo com o olhar dos outros. Tudo isso, porque a identidade precisa ser reconhecida dentro do seio social e validada. Mesmo sendo uma criança, e estando confusa em relaçáo à situaçăo por causa da idade, Isaltina já compreendia que precisava da validaçáo do outro, como podemos notar no trecho em que ela precisou fazer uma cirurgia de apendicite e via neste acontecimento a chance de perceberem que ela na verdade era um menino e através da aprovaçăo médica poder se libertar.

Apesar da dor, eu quase sorria e desejava que tal fato acontecesse. Ali estava a minha chance. O médico iria descobrir quem era eu, lá por debaixo de mim, e contaria para todos. Entâo, o menino que eu carregava, e que ninguém via, poderia soltar as suas asas e voar feliz (EVARISTO, 2016, p. 58) 
Ser reconhecida como um menino para Isaltina era importante porque essa imagem precisava fazer sentido, e isso acontece a partir do momento em que ela espera que náo somente o médico, mas os membros da sua família digam: você é um menino. Contudo, a falta de referência fez com que a personagem se sentisse deslocada e năo pertencente. Pois, como afirma Audre Lorde (2019, p.154) "Como ferramenta de controle social, mulheres foram ensinadas apenas um aspecto das diferenças humanas como legítimas, aquelas que existem entre homens e mulheres." Os outros modos de ser e viver, as inúmeras diferenças de classe, gênero e raça săo consideradas como anormais e desviantes. A personagem sentia-se como se estivesse fora do lugar por náo se sentir representada:

Tanto eu como a minha irmá já estávamos mais sabidinhas. Em pouco tempo, sem que a mamăe-enfermeira soubesse, descobrimos, na rua e nos livros, tudo sobre o corpo da mulher e do homem. Sobre beijos e afagos dos homens para com as mulheres. Lembro-me de que fui invadida por certo sentimento, que năo sei explicar até hoje, uma sensaçáo de estar fora do lugar. (EVARISTO, 2016, p.61)

O sentimento que atravessa a personagem é consequência da imposiçâo de regras e modelos do que é normal e desejável. Os padrôes acabam impossibilitando que o diálogo entre as diferenças sejam estabelecidos. Dessa maneira, exclui da sociedade quem nâo se encaixa nesses moldes. De acordo com Lorde (2019):

A rejeiçấo institucionalizada da diferença é uma necessidade absoluta numa economia centrada no lucro que precisa de outsiders ocupando o papel de pessoas descartáveis. Como integrantes de tal economia, todos fomos programados para responder as diferenças humanas que há entre nós com medo e aversăo, e a lidar com elas de três maneiras: ignorar e, se năo for possível, copiar quando a consideramos dominante ou destruir quando a consideramos subalterna (LORDE, 2019, p.144).

A exclusăo gera nas minorias reaçóes consideradas estratégicas para serem aceitos e sobreviverem. O receio da estigmatizaçấo social leva o sujeito à tentativa de se encaixar nos padróes estabelecidos. Como é apresentado no trecho:

Uma fuga que me garantia certa segurança, já que eu năo me expunha a ninguém, até que um dia um colega de faculdade disse estar encantado por mim. Iniciamos um namoro sem jeito, só de palavras e comedidos gestos. (...) um dia, em que ele desejava beijos e afagos, eu sem desejo algum, sem nada a me palpitar por dentro e por fora, falei da minha vida até ali. Falei do menino que carregava em mim desde sempre. Ele, sorrindo, dizia năo acreditar e apostava que a razăo de tudo deveria ser algum medo que eu trazia escondido no inconsciente. (EVARISTO, 2016, p.63-64)

O reconhecimento da diversidade da sexualidade e do gênero implica no abalo do poder e privilégio masculino mantido pela imposiçáo da submissâo feminina. O mundo patriarcal recusa aceitar as múltiplas identidades de mulheres, pois isso leva ao questionamento e consequentemente a desconstruçâo de uma identidade formada através de critérios subalternizantes para o ser mulher. De acordo com Silva (2012) quando se questiona a identidade questiona-se o poder. Para năo perder o domínio impóe-se a violência.

Afirmava que eu deveria gostar muito e muito de homem, apenas năo sabia. (...) ele iria me ensinar, me despertar, me fazer mulher. E afirmava, com veemência, que 
tinha certeza de meu fogo, pois afinal, eu era uma mulher negra, uma mulher negra... (...) um dia ele me convidou para a festa de seu aniversário e dizia ter convidado outros colegas de trabalho, entre os quais, duas enfermeiras do setor. Fui. Nunca poderia imaginar o que me esperava. Ele e mais cinco homens, todos desconhecidos. Nâo bebo. Um guaraná me foi oferecido. Aceitei. Bastou. Cinco homens deflorando a inexperiência do meu corpo. Diziam eles que estavam me ensinando a ser mulher. (EVARISTO, 2016, p.64)

O estupro coletivo, neste caso, foi motivado pela nâo aceitaçâo da orientaçấo sexual da personagem, pelo racismo e sexismo. O modelo hegemônico heteropatriarcal reprime e ameaça os que se desviam desse padrăo. Contudo, a repetiçăo da afirmaçáo de que Isaltina era uma mulher negra, por isso esse corpo comportava um desejo sexual desmedido comprova que se formou no imaginário coletivo através do discurso brancocêntrico a imagem da negra voluptuosa e pervertida.

[...] Mais que qualquer grupo de mulheres nesta sociedade, as negras tem sido consideradas 'só corpo sem mente'. A utilizaçâo de corpos femininos negros na escravidăo como incubadoras para a geraçấo de outros escravos era exemplificaçáo prática da ideia de mulheres desregradas deviam ser controladas. Para justificar a exploraçăo masculina branca e o estupro das negras durante a escravidăo, a cultura branca teve que produzir a icnografia de corpos de negras que insistia em representá-las como altamente dotadas de sexo, a perfeita encarnaçăo de um erotismo primitivo e desenfreado. (HOOKS, 1995, p. 469)

A identidade essencializada construída para a mulher negra como tentativa de minar sua ascensăo social e política, bem como as velhas identidades baseada no tradicionalismo, por assim dizer, centradas, unificadas e estáveis estăo ameaçadas pela fragmentaçăo. De acordo com Hall o sujeito é:

(...) composto năo de uma única, mas de várias identidades, algumas vezes contraditórias ou náo resolvidas." Correspondentemente, as identidades, que compunham paisagens sociais "lá fora" e que asseguravam nossa conformidade subjetiva com as "necessidades" objetivas da cultura estâo entrando em colapso, como resultado de mudanças estruturais e institucionais. (HALL, 2006, p.12)

Essas mudanças săo provenientes de conflitos políticos e ideológicos causados pela minoria que é subjugada e além disso, nâo se vê representada e cujas velhas identidades nâo fazem sentido. No conto "Isaltina Campo Belo" a personagem é deslocada, e experimenta identidades contraditórias. No primeiro momento se identifica com um menino, a partir do episódio do estupro em que é confrontada, Isaltina passa por mais um momento de identificaçâo na qual descobre que na verdade năo tem um menino dentro de si, mas é uma mulher que nutre desejos pela sua igual. A existência de Isaltina foi ressignificada através da afirmaçâo da sua sexualidade. A personagem compreendeu que ser mulher envolve complexidades e subjetividades diversas.

Năo havia um menino em mim, năo havia nenhum homem dentro de mim. Eu até encarava o estupro como castigo merecido, por năo me sentir seduzida por homens. Naquele momento, sob o olhar daquela moça, me dei permissăo pela primeira vez. Sim, eu podia me encantar por alguém e esse alguém podia ser uma mulher. Eu podia 
desejar a minha semelhante, tanto quanto outras semelhantes minhas desejam o homem. E foi entăo que eu me entendi mulher, igual a todas e diferente de todas que ali estavam. (EVARISTO, 2016, p.66-67)

A escrita de Conceiçăo Evaristo tem o poder de representar os grupos emergentes, acolhendo- os em seu projeto literário. Mostra que as identidades podem ser reconfiguradas, conforme as necessidades individuais e coletivas. Como afirma Hall (2006):

O sujeito assume identidades diferentes em diferentes momentos (...) dentro de nós há identidades contraditórias, empurradas em diferentes direçôes, de tal modo que nossas identificaçóes estâo sendo continuamente deslocadas. (HALL, 2006, p. 13)

É importante frisar que as identidades de Soledad e Isaltina foram construídas a partir de tensionamentos, conflitos e transgressōes. Evaristo ao representar as mulheres negras narrando suas histórias através da escrevivência, contribui para a afirmaçăo de suas identidades. Pois, como afirma Bernd (2003, p.19), "a construçấo da identidade é indissociável da narrativa e consequentemente da literatura". Todavia, diferente da representaçâo sacralizadora, Evaristo mostra as diferenças através da movência identitária. De acordo com Araújo (2018) se pode notar que as marcas identitárias alicerçadas nos valores coloniais conservadores e portanto desfavoráveis às minorias săo moventes, líquidas e provisórias, e que essa realidade pode ser modificada através de estratégias de conscientizaçấo e valorizaçâo cultural. Sendo assim, a obra da escritora Conceiçăo Evaristo é um projeto literário usado como instrumento que denuncia a opressấo racista e sexista. E mostra ao mesmo tempo que ignorar as diferenças causam vulnerabilidades as mulheres negras.

\section{CONSIDERAÇÕES FINAIS}

Os contos "Natalina Soledad" e "Isaltina Campo Belo" funcionam como convite e alerta. No primeiro aspecto, nos convoca a reconhecer que existem diferenças identitárias entre as mulheres negras, e consequentemente necessidades diversas. Dessa maneira desmitifica a visâo essencializante da identidade ligada a raça.

Em segundo plano, chama a atençâo para o fato de que quando se é instituída uma identidade como modelo do bom e correto, com um caráter homogeneizante, acaba por desprezar as demandas das diferenças em prol de interesses que aparentemente engloba o todo, mas, no entanto, emerge de uma particularidade da hegemonia.

A partir dos textos analisados, concluímos que a identidade das mulheres negras foram forjadas sob os moldes que as colocam na posiçáo de subalternidade em razáo da manutençấo do controle e do poder pelo patriarcado. Nos contos, a representaçáo dessa autoridade aparece constantemente simbolizada pela "vara", metáfora do falo. Em "Natalina Soledad", podemos observar que o pai coloca o falo como símbolo de superioridade ao rejeitar a filha e ressaltar em todo o momento o orgulho por ter tido "varóes", e em "Isaltina Campo Belo", o poder falocêntrico aparece por meio do ato de violência no momento do estupro.

Por mais que haja a tentativa de reafirmaçăo de modelos conservadores por meio da imposiçăo, essas identidades têm sido cada vez mais rasuradas, confrontadas e 
reconstruídas. As mulheres negras representadas nos contos recusam ser meros objetos, passivos e se tornam ativas construindo suas identidades que vâo se moldando, contudo de forma conflitante.

As personagens afirmam suas novas identidades através da recusa, insubmissăo. Por assim dizer, elas transgridem para năo sucumbir. Através das múltiplas possibilidades de movências da identidade elas constroem caminhos de liberdade, ou seja, novos modos de existir. Ao incluir a diferença das mulheres negras, Evaristo mobiliza o poder coletivo, fortalecendo suas identidades através da representaçâo literária. Contudo, é importante frisar que, esse fortalecimento e afirmaçăo das identidades năo significam uma fixidez duradoura, mas algo transitório. Pois as identidades se modificam e o fortalecimento năo se dá no sentido de fixá-las, mas de contribuir par uma caminhada de consolidaçáo e fortalecimento do gênero e da raça, de sua força ruma à igualdade de direitos e ao apagamento da opressăo. 


\section{REFERÊNCIAS}

ARAÚJO, Nerivaldo Alves. Identidades ribeirinhas e seus alinhavos em narrativas e na poesia oral das margens do Velho Chico. In: COSTA, E.; ARAÚJO, N.A.; FERNANDES, F. Vozes, performances e arquivos de saberes. Salvador: Eduneb, 2018, p. 291-302.

BERND, Zilá. Literatura e identidade nacional. 2. ed. Porto Alegre: Editora da UFRGS. 2003.

DUARTE, Constância L.; NUNES, Isabella Rosado. Escrevivência: a escrita de nós: reflexôes sobre a obra de Conceiçáo Evaristo. $1^{a}$ Ed. Rio de Janeiro: Mina Comunicaçăo e Arte, 2020.

EVARISTO, Conceiçăo. Insubmissas lágrimas de mulheres. 2. Ed. Rio de janeiro: Malê, 2016.

EVARISTO, Conceiçăo. Da representaçăo à autorrepresentaçăo da mulher negra na literatura brasileira. Disponível em: http://www.palmares.gov.br/sites/000/2/download/52\%20a\%2057.pdf. Acesso em: 31/08/2020

FERNADES, Viviane Barboza.; SOUZA, Maria Cecília Cortez Christiano. Identidade negra entre exclusáo e liberdade. Revista do Instituto Estudos Brasileiros. N. 63. Abri. 2016, p 103-120.

FOUCAULT, Michel. A ordem do discurso. 3. Ed. Săo Paulo: Loyola, 1996.

HALL, Stuart. Identidade cultural na pós-modernidade. 11. ed. Rio de Janeiro: DP\&A, 2006.

HOOKS, Bell. Eu náo sou uma mulher? Mulheres negras e o feminismo. $5^{a}$. Ed. Rio de Janeiro: Rosa dos ventos, 2020.

HOOKS, Bell. Intelectuais negras. Revista estudos feministas. No 2. 1995, p.464- 478.

LORDE, Audre. Idade, raça, classe e sexo: As mulheres negras redefinem a diferença. In:__ (org). Irmă Outsider. $1^{a}$ Ed. Belo Horizonte: Autêntica Editora. 2019, p. 142-156.

SILVA, Tomaz Tadeu da. A produçăo social da identidade e da diferença. In:__ Identidade e diferença: a perspectiva dos estudos culturais. Petrópolis, R J: Vozes, 2012 , p. 73-101. 